\title{
PREVALÊNCIA DO SARAMPO EM CRIANÇAS E PRÉ-ADOLESCENTES NA REGIÃO NORTE E NORDESTE DO BRASIL NO PERÍODO DE 2007 A 2014
}

\author{
PREVALENCE OF MEASLES IN CHILDREN AND PRE-ADOLESCENTS IN \\ THE NORTH AND NORTHEAST REGIONS OF BRAZIL FROM 2007 TO 2014
}

\author{
Bárbara Ferraz Barbosa ${ }^{1}$, Natanael Rodrigues De Souza ${ }^{2}$, Edmy Soza \\ Figueroa ${ }^{3}$.
}

\author{
${ }^{1}$ Universidad de Aquino Bolívia, Santa Cruz de la Sierra, Bolivia. \\ 2Universidade Federal do Sul da Bahia, Teixeira de Freitas, BA, Brasil. \\ 3Universidad Católica San Pablo, Santa Cruz de la Sierra, Bolivia. \\ *bferraz.barbosa@hotmail.com
}

\section{RESUMO}

Doenças exantemáticas são um grupo de infecções sistêmicas contagiosas, que possuem manifestações cutâneas como característica principal, sendo 0 Sarampo e a Rubéola enfermidades de grande incidência no Brasil. Denota-se grande preocupação quanto à primeira por sua alta transmissão, destacando-se no passado por ser uma das principais causas de morbimortalidade infantil. $O$ objetivo do estudo foi verificar a prevalência das enfermidades exantemáticas em crianças e pré-adolescentes do Brasil, no período de 2007 a 2014, analisando particularmente a prevalência do Sarampo no Norte e Nordeste. Trata-se de um estudo epidemiológico, transversal, descritivo realizado por meio de dados secundários do Departamento de Informação em Saúde (DATASUSTABNET), a partir do Sistema de Informação de Agravos de Notificação (SINAN) sobre doenças exantemáticas (Sarampo e Rubéola) no período de 2007 a 2014. Primeiro, foi selecionado todo o Brasil, com filtros para o ano e faixa etária, depois foi analisada a região Norte e Nordeste em relação às notificações de Sarampo em crianças e adolescentes de 0 a 14 anos, analisando faixa etária de maior prevalência e critério de confirmação. Foram registrados 1.833 casos confirmados de doenças exantemáticas: Sarampo e Rubéola, em crianças e préadolescentes de todo o Brasil no período de 2007 a 2014. Sendo o Rio de Janeiro (299), São Paulo (288) e Rio Grande do Sul (233) os estados com maior índice de notificações. Analisando a região Norte e Nordeste do país, quanto à mesma faixa etária e período de tempo, há um total de 759 casos, com alta prevalência nos estados de Paraíba, Pernambuco e Ceará que juntos totalizam $73,6 \%$ do total. Em relação ao Sarampo, no Brasil inteiro houve um total de 431 casos, com maior prevalência no Norte e Nordeste com 389 casos confirmados, sendo a região Nordeste responsável por $99,4 \%$ do total, os estado de Pernambuco com $46 \%$, seguido do Ceará com $41 \%$. Menores índices foram observados no estado de Roraima com 2 casos, Sergipe e Bahia (1 caso/ano cada). No período indicado, as crianças menores de um ano foram as mais afetadas representando $56 \%$, seguidos de 1-4 anos com $29,5 \%$, a faixa etária de menor afetação compreende 5-9 anos com aproximadamente $6 \%$ casos. Segundo o critério de confirmação, o método laboratorial foi o mais utilizado representando $91 \%$, clinico epidemiológico e clinico juntos compreendem a parcela de aproximadamente $7,5 \%$. Conclui-se que há um predomínio nos casos de 
Rubéola em todo o Brasil, porém quando analisada apenas as regiões Norte e Nordeste, há um aumento nos casos de Sarampo, o que deve-se a diversos fatores, sendo necessário um olhar critico relacionado à uma variação na cobertura vacinal, preconizada e distribuída gratuitamente pelo Ministério da Saúde, adjunto a migração de indivíduos não vacinados para o país, assim como aumento do turismo na região de estudo.

Palavras-chave: Doença de Notificação Compulsória. Imunização. Morbillivirus. Sarampo. Vírus do Sarampo. 